\title{
A ACESSIBILIDADE DO PASSAGEIRO COM NECESSIDADE DE ASSISTÊNCIA ESPECIAL: UMA INVESTIGAÇÃO EM VOO COMERCIAL NO BRASIL
}

Marcele Cristiane Minozzo

PPGDesign - Universidade Federal do Paraná

minozzo.marcele@gmail.com

Viviane Gaspar Ribas El Marghani

PPGDesign - Universidade Federal do Paraná

viviane.elmarghani@gmail.com

Resumo: As pessoas com deficiência representam uma parcela considerável da população e têm direito, como qualquer cidadão, ao acesso a serviços com dignidade, incluindo o transporte aéreo. $O$ aumento do número de pessoas que utilizam transporte aéreo no Brasil, pressupõe um aumento também dos passageiros que necessitam de assistência especial. Pesquisas apontam que muitos passageiros encontram dificuldades na acessibilidade, apesar dos recentes investimentos no setor aeroportuário. $O$ objetivo deste artigo é identificar quais os problemas ainda existem e esclarecer quais os pontos de maior dificuldade para estas pessoas. Para tanto, foi realizada uma revisão dos estudos em acessibilidade em aeronaves e um percurso acompanhado em voo nacional. Verificou-se que ainda há muitos problemas no que tange a acessibilidade, principalmente no interior da cabine de passageiros.

Palavras-chave: Acessibilidade, transporte aéreo, pessoa com deficiência, cabine de passageiros.

\begin{abstract}
People with disabilities represent a significant portion of the population, and thereby they have the rights to access services with dignity, including air transport as any citizen. The number of air transport users in Brazil has been incrising, this way there is an increase in the number of passengers who require special assistance as well. Researches indicate that many passengers find difficulties in the accessibility, despite recent investments in the airport sector. The purpose of this paper is to identify what problems still exist and clarify points of greatest difficulty. Therefore, a review of accessibility studies on aircraft and an accompanied route in national flight was performed. It was found that there are still many problems with respect to accessibility, especially inside the passenger cabin.
\end{abstract}

Keywords: Accessibility, Air Transport, People with disabilities, Cabin. 


\section{INTRODUÇÃO}

No último censo realizado no Brasil, 23,91\% da população declarou ter algum grau de deficiência (IBGE, 2010). As pessoas com deficiência e pessoas com mobilidade reduzida têm o mesmo direito que os demais cidadãos à livre circulação, liberdade de escolha e de não discriminação. Isso se aplica ao transporte aéreo como a outras áreas da vida (EC, 2006). No campo da aviação comercial, no Brasil, o Passageiro com Necessidade de Assistência Especial (PNAE), é definido como:

a pessoa com deficiência, pessoa com idade igual ou superior a 60 (sessenta) anos, gestante, lactante, pessoa acompanhada por criança de colo, pessoa com mobilidade reduzida ou qualquer pessoa que por alguma condição específica tenha limitação na sua autonomia como passageiro. (ANAC, 2013, p.1)

O setor de transporte aéreo cresceu muito nos últimos anos e a perspectiva é de um aumento ainda maior. O Brasil é o terceiro maior mercado doméstico de aviação civil no mundo, atrás apenas de Estados Unidos e China. Quatro grandes empresas que operam no país representam mais de $7 \%$ do mercado no cenário internacional, sendo elas a TAM, Gol, Azul e Avianca (ABEAR, 2015).

Eventos esportivos internacionais como a Copa do Mundo de Futebol, realizada no Brasil em 2014, e as Olimpíadas do Rio de Janeiro em 2016 geraram um aumento na demanda e maiores investimentos no setor. $O$ Brasil se prepara para receber mais de 600 milhões de passageiros por ano em 2034. Por isso foram investidos 15,6 bilhões de reais no setor de transporte aéreo doméstico no Brasil entre os anos de 2004 e 2014. (BRASIL, 2015).

A democratização do transporte aéreo nos últimos dez anos, com redução de $48 \%$ no custo da passagem doméstica, também levou a um aumento no número de passageiros, que alcançou 117 milhões em 2014. A escolha da forma de viajar dos brasileiros é influenciada por três fatores: custo, tempo e conforto. (BRASIL, 2015). Num país com grande extensão, como é o caso do Brasil, a opção pelo transporte aéreo mostra-se cada vez mais frequente.

O brasileiro está viajando mais e a tendência é que este cenário melhore nos próximos 20 anos. Um aumento no número de passageiros pressupõe um aumento também no número de PNAEs que buscam o transporte aéreo como alternativa. $O$ que leva ao questionamento: Este setor está preparado para oferecer um serviço adequado a estes passageiros?

Importante esclarecer que este grupo de pessoas é heterogêneo e que para cada deficiência há necessidades diferentes. Neste estudo foram consideradas apenas as pessoas com deficiência físico-motora ou que tenham sua mobilidade reduzida temporária ou permanentemente.

O objetivo deste artigo é identificar quais os problemas ainda existem e esclarecer quais os pontos onde o PNAE mais encontra dificuldade. Para tanto foi realizada uma revisão nos estudos em acessibilidade. Para comparar os dados teóricos com a realidade atual foi realizado um percurso acompanhado com uma PNAE em um voo comercial em território nacional. 


\section{ACESSIBILIDADE EM AERONAVES}

Através de uma investigação nas leis brasileiras que regulam a acessibilidade no transporte aéreo e de uma Revisão Bibliográfica nos estudos já realizados sobre o tema fez-se o levantamento teórico utilizado e que será depois comparado com os dados empíricos. $O$ resultado desta investigação será descrito a seguir.

\subsection{Regulamentação de Acessibilidade no Transporte Aéreo}

A legislação brasileira, no que se refere ao transporte aéreo, define como regulatória a Resolução № 280 da ANAC, de 11 de julho de 2013. Neste documento estão previstos os itens descritos no Quadro 1.

\section{Quadro 1 - REGULAMENTAÇÃO DE ACESSIBILIDADE PNAE}

\begin{tabular}{|l|l|}
\hline ITENS & REGULAMENTAÇÃO \\
\hline $\begin{array}{l}\text { Configuração } \\
\text { da Aeronave }\end{array}$ & $\begin{array}{l}\text { Aeronaves com } 30 \text { ou mais assentos devem ter metade dos assentos de } \\
\text { corredor com descanso de braço móvel, em todas as classes de serviço da } \\
\text { aeronave, proporcionalmente distribuídos. } \\
\text { Aeronaves com } 100 \text { ou mais assentos devem dispor de pelo menos uma } \\
\text { cadeira de rodas de bordo. }\end{array}$ \\
\hline $\begin{array}{l}\text { Embarque e } \\
\text { Desembarque }\end{array}$ & $\begin{array}{l}\text { O embarque do PNAE deve ser prioritário. } \\
\text { Preferencialmente por pontes de embarque, podendo também ser } \\
\text { realizados por equipamento de ascenso e descenso ou rampa. }\end{array}$ \\
\hline Acompanhante & $\begin{array}{l}\text { Quando necessário acompanhante, a companhia aérea deve prover sem } \\
\text { cobrança adicional, ou cobrar pelo assento do acompanhante valor igual ou } \\
\text { inferior a 20\% do valor do bilhete aéreo adquirido pelo PNAE. O } \\
\text { acompanhante deve ser maior de 18 anos e possuir condições de prestar } \\
\text { auxílio nas assistências necessárias ao PNAE. O acompanhante deve viajar } \\
\text { na mesma classe e em assento adjacente ao do PNAE que esteja assistindo }\end{array}$ \\
\hline $\begin{array}{l}\text { Atendimento a } \\
\text { Bordo }\end{array}$ & $\begin{array}{l}\text { A companhia deve prestar assistência ao PNAE no embarque e } \\
\text { desembarque da aeronave; acomodação no assento, incluindo o } \\
\text { deslocamento dentro da aeronave; acomodação da bagagem de mão; } \\
\text { condução às instalações sanitárias. }\end{array}$ \\
\hline $\begin{array}{l}\text { Transporte de } \\
\text { Equipamentos } \\
\text { de Tecnologia } \\
\text { Assistiva }\end{array}$ & $\begin{array}{l}\text { A companhia deve transportar gratuitamente o equipamento empregado } \\
\text { para locomoção do PNAE na cabine da aeronave, quando houver espaço } \\
\text { ao PNAE no mo compartimento de bagagem, devendo ser disponibilizada } \\
\text { equipamento médico a ser utilizado durante o voo deve ser transportado } \\
\text { na cabine. Os equipamentos médicos do PNAE, quando despachados, } \\
\text { devem ser considerados itens frágeis e prioritários, devendo ser } \\
\text { transportados no mesmo voo. No caso de extravio ou avaria a companhia } \\
\text { deve providenciar a substituição imediata por item equivalente. E deve } \\
\text { oferecer desconto de, no mínimo, 80\% no valor cobrado pelo excesso de } \\
\text { bagagem, exclusivamente para o transporte de Tecnologias Assistivas } \\
\text { indispensáveis ao PNAE. }\end{array}$ \\
\hline
\end{tabular}

Fonte: Elaborado pelas autoras, com base em ANAC (2013)

\subsection{Revisão dos Estudos em Acessibilidade em Aeronaves}

Foi realizada, no Portal de Periódicos da Capes, uma Revisão Bibliográfica Assistemática, utilizando as mesmas palavras-chave deste artigo. Foram selecionados 
estudos recentes, publicados a partir de 2010, para fundamentar o estudo. Também foram consultadas as referências relevantes, mais citadas, destes trabalhos.

Castro (2010) fez um estudo qualitativo em parceria com duas ONGs do Rio de Janeiro, a fim de identificar as dificuldades levantadas por pessoas com deficiência no turismo em viagens de avião. O embarque e o desembarque foram apontados como momentos que causam constrangimento aos PNAEs, principalmente se forem remotos, sem as pontes de embarque. $O$ uso do toalete foi um ponto citado como muito limitante. A falta de espaço e privacidade dos toaletes faz com que as pessoas evitem se alimentar ou beber durante o voo para não precisarem usar o banheiro. Da mesma forma, a falta de autonomia para ir e vir, criada pelas cadeiras de bordo, que não podem ser operadas sem ajuda, são vistas como limitantes. Barreiras atitudinais também foram mencionadas, pelo tratamento inadequado de funcionários mal treinados para auxiliar os PNAE. O autor defende que o transporte aéreo só será efetivamente um meio de inclusão se os deficientes forem ouvidos.

Poria, Reichel e Brandt (2010) realizaram um estudo exploratório sobre as experiências de voo de pessoas com deficiência em viagens internacionais. Através do relato de 45 pessoas com deficiência e mobilidade reduzida, os autores investigaram quais as dificuldades sentidas em todas as etapas da viagem, como elas as enfrentaram as situações e as sugestões de melhorias apontadas por elas. Os autores relatam que as etapas pré-embarque e após o voo foram apontadas como importantes pelos entrevistados, tanto quanto o voo em si. E que o embarque prioritário é aprovado pelas pessoas com deficiência, pois evita pressão e constrangimento ao atrasar o embarque dos outros passageiros. Pessoas com mobilidade reduzida, que utilizam muletas, também manifestaram vontade de embarque preferencial, já que as filas são grandes e seus movimentos são lentos.

Os cadeirantes apontam como dificuldade deixar a cadeira de rodas própria para utilizar a cadeira de rodas de bordo, que é descrita por eles como muito desconfortável. Além disso, a cadeira de bordo exige auxílio de outra pessoa nos deslocamentos, o que prejudica a autonomia dos passageiros. Também relatam acidentes constrangedores pela dificuldade e consequente demora de acesso ao toalete. Afirmam adotar estratégias para evitar esta necessidade, como evitar beber antes do voo. Isto pode ser muito perigoso, principalmente se houver atrasos, pois os PNAEs podem ficar desidratados (PORIA; REICHEL; BRANDT, 2010).

A tripulação não se mostra preparada para auxiliar pessoas com diferentes tipos de deficiência, muitas vezes respondem ao acompanhante e tratam os deficientes físicos como se tivessem deficiência cognitiva (PORIA; REICHEL; BRANDT, 2010), (CHANG; CHEN 2012).

Outra reclamação foi em relação ao apoio de braço, que, se não for totalmente embutido, pode machucar as costas na transferência para a poltrona (PORIA; REICHEL; BRANDT, 2010).

Chang e Chen (2011) em seu estudo, procuraram entender as necessidades e desejos das pessoas com deficiência em voos, através da aplicação de uma análise de importância/desempenho. Embarque prioritário, escolha das poltronas, assistência no embarque e atitudes da tripulação foram apontadas como muito importantes, já que a maioria destas pessoas despacha seus equipamentos assistivos e é conduzida por familiares ou equipe de terra para o embarque. 
A distância entre poltrona e toalete, a falta de toaletes acessíveis e de cadeiras de rodas de bordo, assim como a necessidade de ajuda para acessar os toaletes foram citadas como situações que podem criar situação desconfortável (CHANG, CHEN, 2011).

Os autores afirmam que quanto maior o grau de comprometimento da mobilidade, menor a satisfação com os serviços prestados a bordo. Pessoas com deficiências mais severas sentem mais a falta de acessibilidade.

Chang; Chen (2012) estudam os fatores que determinam as escolhas das pessoas com mobilidade reduzida em viagens internacionais. Os autores dividem a viagem internacional em estágios: pré-viagem (planejamento), pré-embarque, a bordo da aeronave, pós-voo, e a experiência no destino.

Dificuldades em qualquer ponto podem desencorajar a viagem. No aeroporto, o piso antiderrapante foi mencionado como uma necessidade importante. Nos serviços a bordo dois problemas principais foram apontados: a falta de toaletes acessíveis e a possível necessidade de auxílio dos comissários para deslocamentos e uso dos toaletes. Estes problemas podem fazer do voo uma experiência desagradável e até humilhante. Além disso, o espaço do corredor é limitado e dificulta deslocamentos internos (CHANG; CHEN, 2012).

O transporte de equipamentos de tecnologia assistiva também preocupa os PNAEs. Danos na cadeira de rodas podem comprometer toda a viagem, causando impedimento de locomoção (CHANG; CHEN, 2012).

Souza (2014) discute a interação entre os atores sociais que afetam a acessibilidade de PNAEs nas viagens de avião: os órgãos reguladores, os passageiros, os operadores (aeroportuários e aéreos) e fabricantes de aeronaves. A autora verificou que o problema maior é na deficiência do serviço dos operadores aeroportuários e companhias aéreas e na inadequação das aeronaves, frente às reais necessidades destes passageiros.

As maiores dificuldades dos passageiros são: a falta de acessibilidade nos toaletes, a falta de equipamentos para embarque e desembarque adequados e falta de treinamento dos funcionários. Outro problema mencionado foi que os apoios de braços não são móveis na primeira fileira, justamente a reservada para os PNAE, dificultando a transferência para a poltrona (SOUZA, 2014).

A autora afirma que as regulamentações devem ser elaboradas em conjunto com os usuários para evitar estas lacunas, e que deve existir maior fiscalização, uma vez que muitos itens são regulamentados, mas não são cumpridos. Mesmo que haja regulamentação proibindo a prática ainda há passageiros que embarcam carregados manualmente, por exemplo. Outros itens sequer são regulamentados. A resolução 280 ANAC não faz menção à acessibilidade do toalete, nem ao dimensionamento de corredores ou entre os assentos (SOUZA, 2014).

As cabines de aeronaves atuais não estão adequadas para o transporte dos usuários com suas respectivas tecnologias assitivas. A cadeira de rodas pessoal é o item de maior dificuldade, visto que os corredores das aeronaves são estreitos, impedindo seu uso, e não há espaço adequado para seu armazenamento a bordo. Com um projeto de Design Universal ${ }^{1}$, corredores mais largos beneficiariam, além dos

\footnotetext{
Vertente que surgiu na Universidade da Carolina do Norte, EUA, em 1998. O Design Universal
considera a variedade de habilidades humanas no projeto de um produto, ambiente ou serviço. (STORY, MUELLER E MACE, 1998)
} 
cadeirantes, pessoas com outros equipamentos, como andadores e muletas (CAMPESE, 2014).

Com o objetivo de comparar os dados da literatura com a atual situação de acessibilidade do setor aéreo foi realizado um percurso acompanhado em um voo nacional.

\section{PERCURSO ACOMPANHADO}

O percurso acompanhado é uma adaptação do método de passeio acompanhado desenvolvido por Dischinger (DA LUZ et al., 2013), que consiste em "acompanhar uma pessoa com características relevantes ao estudo por um percurso com atividades definidas, sem conduzir, apenas seguindo-a. Durante o procedimento, registram-se as reações, dificuldades ou facilidades apresentadas". Segundo as autoras este método é importante por que é o próprio usuário quem avalia o espaço.

A PNAE voluntária desta pesquisa foi selecionada por ser cadeirante e corresponder, portanto, às características necessárias à investigação. Também por ser uma viajante frequente, que realiza viagens de avião pelo Brasil de 3 a 4 vezes por ano.

O percurso foi entre Curitiba e João Pessoa, com conexão e troca de aeronave no Rio de Janeiro.

O trajeto foi definido por ser habitual da PNAE, e por apresentar uma conveniente diversidade de aeroportos. O Aeroporto Internacional Afonso Pena em Curitiba foi eleito como melhor aeroporto do país pelos passageiros em 2015 (GAZETA DO POVO, 2016). O aeroporto internacional Tom Jobim no Rio de Janeiro, está entre os maiores do país em movimentação ${ }^{2}$ de passageiros. A conexão neste foi importante também para verificar se as melhorias divulgadas ocorreram com a proximidade dos Jogos Olímpicos e Paralímpicos.

Embora João Pessoa faça parte dos roteiros turísticos, seu Aeroporto Internacional Presidente Castro Pinto, movimentou pouco mais de 1,4 milhões de passageiros em 2015 (INFRAERO, 2016). São três cenários bastante distintos e que representam a diversidade encontrada no Brasil.

O primeiro passo foi explicar para a PNAE o método, os objetivos e o trajeto pré-definido (Figura 1). 


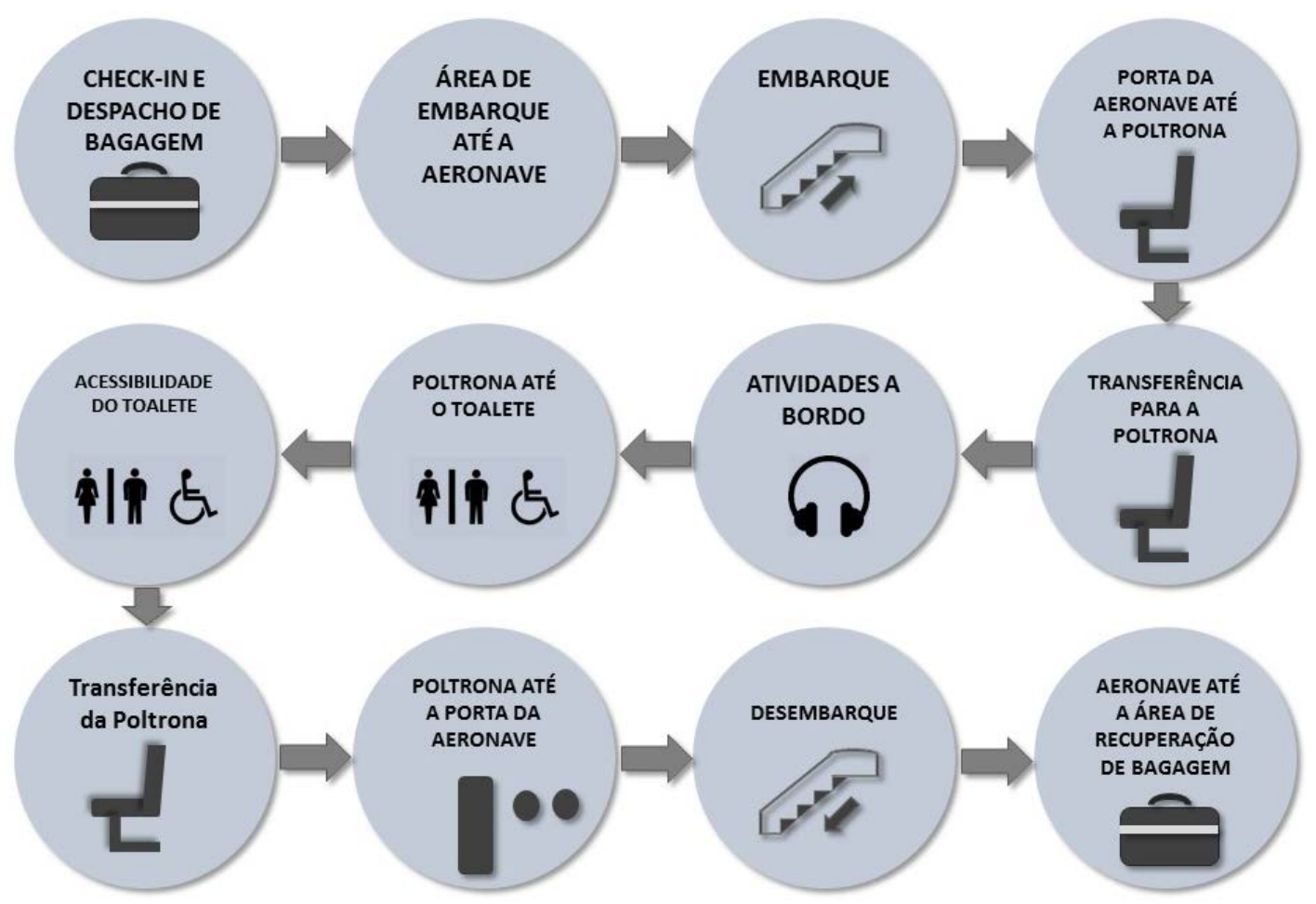

Figura 1 - ETAPAS DO PERCURSO ACOMPANHADO.

Fonte: Elaborada pelas autoras, com base na pesquisa realizada.

Quadro 2 - PERCURSO ACOMPANHADO - ETAPAS DO PRIMEIRO TRECHO

\begin{tabular}{|c|c|c|}
\hline \multicolumn{3}{|c|}{ Trecho: Curitiba - Rio de Janeiro } \\
\hline Data: 15/12/2015 & Tempo de voo: $1 \mathrm{~h} 30 \mathrm{~min}$ & $\begin{array}{l}\text { Modelo Aeronave: Boeing } 737 \\
700\end{array}$ \\
\hline PNAE - tetraparesia & Sexo: feminino & Idade: 30 anos \\
\hline Etapas do Percurso & Pontos Positivos & Pontos negativos \\
\hline $\begin{array}{l}\text { Check-in e Despacho de } \\
\text { bagagem }\end{array}$ & $\begin{array}{l}\text { Não foi cobrado excesso de } \\
\text { bagagem pelo despacho das } \\
\text { ajudas técnicas. }\end{array}$ & $\begin{array}{l}\text { As cotas da PNAE e da } \\
\text { pesquisadora, que não } \\
\text { despachou, foram somadas }\end{array}$ \\
\hline Embarque Prioritário & $\begin{array}{l}\text { Embarque prioritário da PNAE e } \\
\text { da acompanhante }\end{array}$ & - \\
\hline $\begin{array}{l}\text { Área de Embarque até a } \\
\text { Aeronave }\end{array}$ & $\begin{array}{l}\text { Auxílio de Funcionário da Cia } \\
\text { aérea }\end{array}$ & $\begin{array}{l}\text { PNAE não pode utilizar cadeira } \\
\text { de rodas própria }\end{array}$ \\
\hline Embarque & Pontes de embarque & $\begin{array}{l}\text { Degrau alto entre a ponte e o } \\
\text { piso da aeronave }\end{array}$ \\
\hline $\begin{array}{l}\text { Porta da Aeronave até a } \\
\text { Poltrona }\end{array}$ & Auxílio dos Comissários & $\begin{array}{l}\text { Carregada manualmente. } \\
\text { Cadeira de rodas não entra no } \\
\text { corredor. }\end{array}$ \\
\hline $\begin{array}{l}\text { Transferência para } \\
\text { poltrona }\end{array}$ & - & $\begin{array}{l}\text { Poltrona preferencial não tem } \\
\text { braço móvel, o que dificulta a } \\
\text { transferência. }\end{array}$ \\
\hline $\begin{array}{l}\text { Armazenamento de } \\
\text { Bagagem }\end{array}$ & Auxílio dos Comissários & - \\
\hline $\begin{array}{l}\text { Procedimentos de } \\
\text { segurança }\end{array}$ & Auxílio dos comissários & - \\
\hline
\end{tabular}




\begin{tabular}{|c|c|c|}
\hline Auxílio da Tripulação & Tripulação atenciosa & - \\
\hline $\begin{array}{l}\text { Utilização do } \\
\text { Entretenimento }\end{array}$ & - & $\begin{array}{l}\text { Não foram disponibilizados } \\
\text { quaisquer equipamentos }\end{array}$ \\
\hline $\begin{array}{l}\text { Utilização da Mesa de } \\
\text { Refeições }\end{array}$ & - & $\begin{array}{l}\text { Voo sem serviço de bordo. } \\
\text { Mesa de refeições lateral, } \\
\text { embutida no apoio de braço. } \\
\text { Exige movimentos de torção e } \\
\text { força para acioná-la. }\end{array}$ \\
\hline Poltrona até o toalete & - & Não realizado \\
\hline Acessibilidade do toalete & - & $\begin{array}{l}\text { A cadeira de rodas de bordo } \\
\text { não entra totalmente no } \\
\text { toalete. A porta fica aberta e } \\
\text { não há espaço para o } \\
\text { acompanhante auxiliar na } \\
\text { transferência. }\end{array}$ \\
\hline $\begin{array}{l}\text { Transferência da } \\
\text { Poltrona para cadeira de } \\
\text { rodas da cia aérea }\end{array}$ & - & $\begin{array}{l}\text { Carregada manualmente pelos } \\
\text { comissários }\end{array}$ \\
\hline Desembarque & Pontes de embarque & - \\
\hline $\begin{array}{l}\text { Acesso à Área de } \\
\text { Desembarque }\end{array}$ & $\begin{array}{l}\text { Auxílio de funcionário da Cia } \\
\text { que declarou ser treinado para } \\
\text { atendimento de PNAE. }\end{array}$ & - \\
\hline
\end{tabular}

Fonte: Elaborado pelas autoras, com base na pesquisa realizada

Quadro 3 - PERCURSO ACOMPANHADO - ETAPAS DO SEGUNDO TRECHO

\begin{tabular}{|c|c|c|}
\hline \multicolumn{3}{|c|}{ Trecho: Rio de Janeiro - João Pessoa } \\
\hline Data: 15/12/2015 & Tempo de voo: $2 \mathrm{~h} 58 \mathrm{~min}$ & $\begin{array}{l}\text { Modelo da Aeronave: Boeing } \\
737700\end{array}$ \\
\hline PNAE - tetraparesia & Sexo: feminino & Idade: 30 anos \\
\hline Etapas do Percurso & Pontos Positivos & Pontos negativos \\
\hline Embarque Prioritário & - & $\begin{array}{l}\text { Voo de conexão, já havia } \\
\text { passageiros a bordo. PNAE foi } \\
\text { acomodada em assento } \\
\text { preferencial, acompanhante em } \\
\text { outra fileira. }\end{array}$ \\
\hline $\begin{array}{l}\text { Área de Embarque até a } \\
\text { Aeronave }\end{array}$ & $\begin{array}{l}\text { Translado em ônibus adaptado } \\
\text { com auxílio de funcionário da } \\
\text { Cia aérea }\end{array}$ & 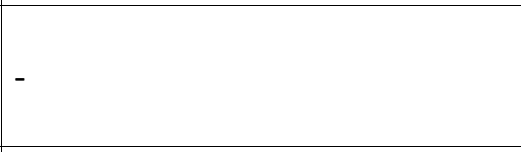 \\
\hline Embarque & $\begin{array}{l}\text { Embarque com Ambulift do } \\
\text { Terminal Aeroportuário }\end{array}$ & 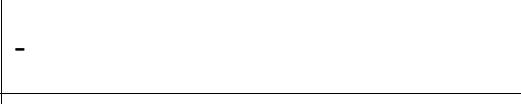 \\
\hline $\begin{array}{l}\text { Porta da Aeronave até a } \\
\text { Poltrona }\end{array}$ & 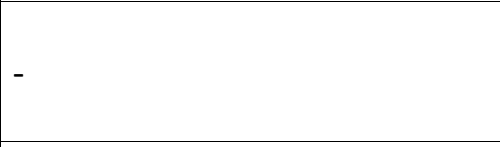 & $\begin{array}{l}\text { Carregada manualmente. } \\
\text { Cadeira de rodas não entra no } \\
\text { corredor. }\end{array}$ \\
\hline $\begin{array}{l}\text { Transferência para } \\
\text { poltrona }\end{array}$ & - & $\begin{array}{l}\text { Carregada manualmente. } \\
\text { Poltrona preferencial não tem } \\
\text { braço móvel, o que impede a } \\
\text { transferência autônoma. }\end{array}$ \\
\hline $\begin{array}{l}\text { Armazenamento de } \\
\text { Bagagem }\end{array}$ & Auxílio dos Comissários & - \\
\hline
\end{tabular}




\begin{tabular}{|l|l|l|}
\hline $\begin{array}{l}\text { Procedimentos de } \\
\text { segurança }\end{array}$ & Auxílio dos comissários & - \\
\hline $\begin{array}{l}\text { Utilização do } \\
\text { Entretenimento }\end{array}$ & - & $\begin{array}{l}\text { Não foram disponibilizados } \\
\text { quaisquer equipamentos }\end{array}$ \\
\hline $\begin{array}{l}\text { Utilização da Mesa de } \\
\text { Refeições }\end{array}$ & - & $\begin{array}{l}\text { Serviço de bordo cancelado por } \\
\text { turbulências. Mesa de refeições } \\
\text { lateral, embutida no apoio de } \\
\text { braço. Exige movimentos de } \\
\text { torção e força para acioná-la. }\end{array}$ \\
\hline Auxílio da Tripulação & Tripulação atenciosa & - \\
\hline Poltrona até o toalete & - & Não realizado \\
\hline $\begin{array}{l}\text { Acessibilidade do } \\
\text { lavatório }\end{array}$ & - & $\begin{array}{l}\text { Cadeira de rodas de bordo não } \\
\text { entra totalmente no toalete. A } \\
\text { porta fica aberta e não há } \\
\text { espaço para o acompanhante } \\
\text { auxiliar na transferência. }\end{array}$ \\
\hline $\begin{array}{l}\text { Transferência da } \\
\text { Poltrona para cadeira de } \\
\text { rodas da cia aérea }\end{array}$ & - & Manualmente pelos comissários \\
\hline Desembarque & $\begin{array}{l}\text { Cadeira Lagarta, com auxílio dos } \\
\text { comissários }\end{array}$ & $\begin{array}{l}\text { PNAE sentiu-se desconfortável } \\
\text { nesta cadeira. Desembarque } \\
\text { sujeito a intempéries. }\end{array}$ \\
\hline $\begin{array}{l}\text { Acesso à Área de } \\
\text { Desembarque }\end{array}$ & $\begin{array}{l}\text { Auxílio de funcionário da Cia } \\
\text { aérea }\end{array}$ & - \\
\hline Fonte: Elaborado pelas autoras, com base na pesquisa realizata
\end{tabular}

Fonte: Elaborado pelas autoras, com base na pesquisa realizada

Através do percurso acompanhado pôde-se perceber que há muitos pontos que precisam ser melhorados em termos de acessibilidade e inclusão no transporte aéreo. Foram 17 pontos avaliados pela PNAE como positivos e 19 como negativos.

A compra das passagens da PNAE e da pesquisadora foi realizada via internet e o site da Cia aérea não ofereceu a opção de desconto previsto em lei para o acompanhante. No entanto, no check-in o bilhete foi emitido como prioritário para as duas passageiras, bem como a acomodação nas poltronas preferenciais.

A PNAE normalmente transporta vários equipamentos de tecnologia assistiva: cadeira de rodas, andador e sonda, além das bagagens usuais. A cobrança de taxa de excesso de bagagem pelo transporte de tecnologias assitivas é relatada por ela como frequente, embora não tenha ocorrido neste voo, pois as cotas da passageira e da pesquisadora (que nada despachou) foram somadas.

A impossibilidade de embarcar utilizando sua própria cadeira de rodas e transportá-la na cabine limitou a autonomia da PNAE. A cadeira de rodas da Companhia aérea não possui as adaptações necessárias para ser manuseada pela passageira como a sua própria.

O embarque foi prioritário, realizado por pontes de embarque no primeiro trecho (Figura 2) e por ambulift ${ }^{3}$ no segundo, mas a transferência para a poltrona foi por carregamento manual (Figura 3), pela impossibilidade de acessar o estreito corredor da aeronave com a cadeira de rodas da Companhia aérea. As poltronas preferenciais possuem apoios de braço fixos, o que inviabilizaria a transferência autônoma, de qualquer maneira.

3 Veículo adaptado com uma plataforma elevatória. 


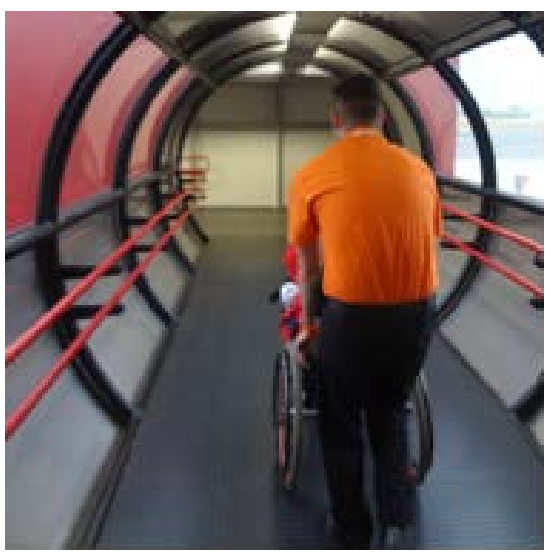

Figura 2 - EMBARQUE POR PONTE DE EMBARQUE

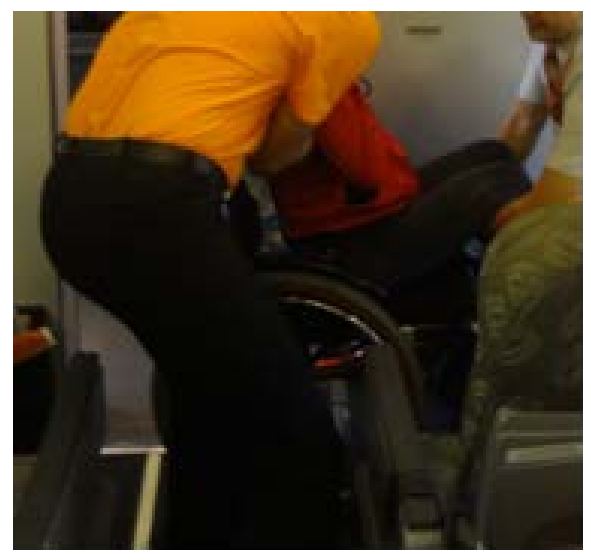

Figura 3 - TRANSFERÊNCIA MANUAL

Fonte: Elaborada pelas autoras, com base na pesquisa realizada.

O toalete da aeronave não oferece privacidade pois não há espaço para a cadeira de rodas de bordo em seu interior, o que não permite transferência com a porta fechada (Figura 4). As dimensões reduzidas também não permitem a presença do acompanhante. A PNAE utiliza sonda e não consegue fazê-lo sozinha, necessita de auxílio, portanto não utiliza o toalete da aeronave. Neste caso o tempo de conexão é um ponto importante na escolha do voo, já que há limite de intervalo para procedimento de sonda.

O translado na troca de aeronaves foi realizado em ônibus adaptado com auxílio de funcionário da Companhia aérea (Figura 5).

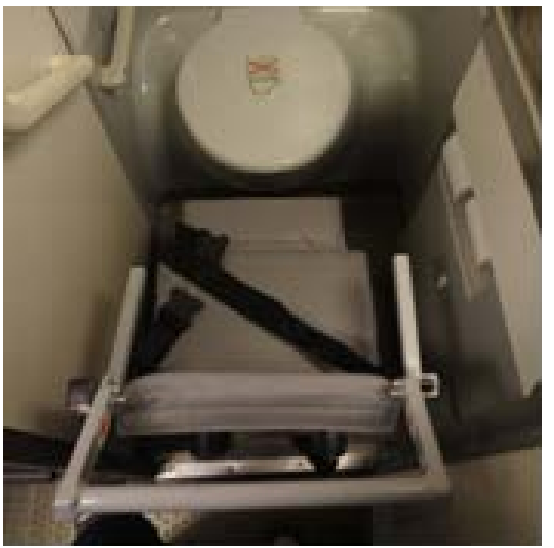

Figura 4 - ACESSIBILIDADE DO TOALATE. Figura 5 - TRANSLADO NA CONEXÃO.

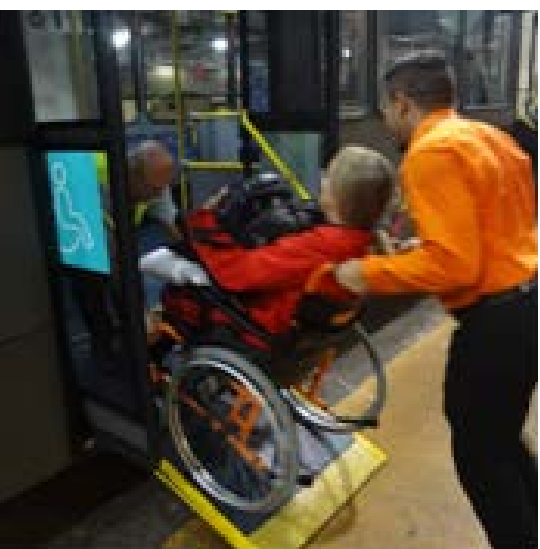

pesquisa realizada.

O desembarque no Rio de Janeiro foi realizado por pontes de embarque, mas em João Pessoa não há esta estrutura. Foi utilizada uma cadeira lagarta ${ }^{4}$ (Figura 6) que, embora seja regulamentada, causou sensação de insegurança para a passageira. Outro fator de desconforto foi que no momento do desembarque garoava, o que deixa o desembarque por escadas, que ficam escorregadias com a umidade, mais arriscado também para os demais passageiros. 


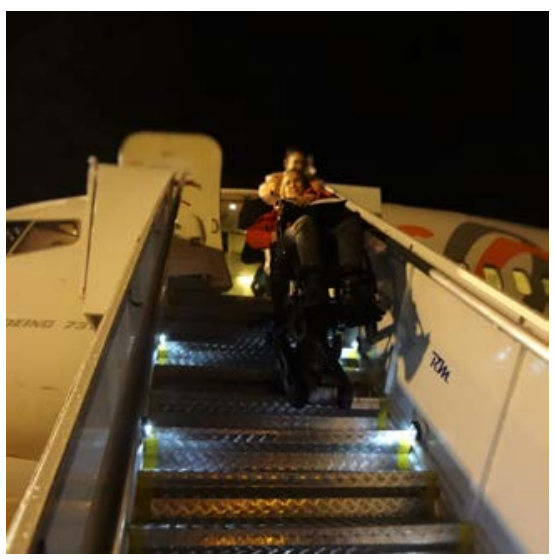

Figura 6 - DESEMBARQUE EM CADEIRA LAGARTA

Fonte: Elaborada pelas autoras,com base na pesquisa realizada.

\section{CONCLUSÃO}

Embora a Resolução № 280 da ANAC regulamente os direitos do PNAE, não são abordados itens importantes, como as dimensões mínimas para corredores de aeronaves e a acessibilidade do toalete.

Nos estudos sobre acessibilidade no transporte aéreo pôde-se perceber que ainda são muitas as dificuldades dos PNAEs. A falta de espaço nos corredores e lavatórios é uma questão abordada em muitas pesquisas. O dimensionamento dos corredores e das poltronas não atende a população em sua diversidade.

O embarque e desembarque, quando não há pontes de embarque, é um momento que causa insegurança e constrangimento. A cadeira de rodas de bordo é descrita como desconfortável e mesmo as cadeiras fornecidas pelas companhias aéreas não entram no corredor, exigindo transferência manual, o que limita a autonomia do passageiro. A utilização da própria cadeira de rodas é um desejo de muitos passageiros, mas as cabines atuais não são adequadas para sua utilização nem armazenamento a bordo. Corredores mais largos, como sugere Campese (2014), facilitariam o acesso destas pessoas com mais conforto e dignidade.

Pôde-se perceber no percurso acompanhado que os aeroportos de maior circulação estão melhor preparados, com pessoal treinado e equipamentos adequados.

No aeroporto de João Pessoa, que recebe menos passageiros, não há pontes de embarque nem ambulift, mas uma cadeira lagarta que, embora seja um equipamento regulamentado, causou desconforto e insegurança à passageira. Outro fator negativo é que em desembarques remotos os passageiros estão expostos a intempéries

Na cabine de passageiros, a falta de espaço para a movimentação da cadeira de rodas da companhia aérea exige a transferência manual. $O$ apoio de braços fixo nas poltronas preferenciais não permite transferência autônoma. A PNAE em questão poderia se movimentar e fazer a transferência sozinha, se houvesse espaço, e se a poltrona estivesse no mesmo nível da cadeira de rodas.

O toalete não foi utilizado, pois as dimensões limitadas impedem o fechamento da porta quando a cadeira de rodas de bordo está em seu interior, ou seja, não oferece privacidade.

Conclui-se, portanto, que há necessidade de investimento em pesquisa e soluções de Design, principalmente para o interior da cabine. Que a regulamentação 
em muitos pontos é falha. E mesmo os pontos que são regulamentados devem ser melhor fiscalizados.

A limitação de tempo e financeira não permitiu a realização de voos em outros trechos, então este pode ser o resultado de uma situação específica. A sugestão para trabalhos futuros seria a uma investigação em outros percursos e propostas de melhorias.

\section{REFERÊNCIAS}

ABEAR - Associação Brasileira Das Empresas Aéreas. Democratização aérea na corda bamba. Artigos, 18/05/2015. Disponível na internet por http em:

<http://www.abear.com.br/imprensa/artigos/mostrar/democratizacao-aerea-nacorda-bamba>. Acesso em 06 fev. 2016

ANAC - Agência Nacional de Aviação Civil. Resolução n 280, de 11 de julho de 2013. $17 p$.

BRASIL. Secretaria de Aviação Civil. 0 cenário da aviação no Brasil. Disponível na internet por http em: <http://www.aviacao.gov.br/obrasilquevoa/cenario-da-aviacaobrasileira.php> Acesso em 26 out. 2015

CAMPESE, Carina. Cabine de aeronaves e tecnologia assistiva: contribuições para um estudo de prospecção. Dissertação. Mestrado em Engenharia de Produção. São Carlos: 2014. 203p.

CASTRO, Rafael Teixeira. Acessibilidade de turistas com necessidades especiais ao transporte aéreo. Dissertação. Mestrado em Engenharia de Transportes. Universidade Federal do Rio de Janeiro. 2010. 153p.

CHANG, Yu-CHUN; CHEN, Ching-Fu. Identifying mobility needs for disabled air passengers. Tourism Management. 32, 2011 p. 1214-1217.

CHANG, Yu-CHUN; CHEN, Ching-Fu. Overseas travel choice for persons with reduced mobility. Journal of Air Transport Management 20, 2012 p. 43-45.

DA LUZ, G. H.; HEINISCH, L. M.; DOLRNELES, V. G.; BINS ELY, V. H. M. Acessibilidade e apropriação em espaços abertos. Florianópolis: PET/ ARQ/ UFSC, 2013. 241 p.

EC. European Commission. Regulation n⿳1107/2006 of The European Parliament and of the Council of 5 July 2006 concerning the rights of disabled persons and persons with reduced mobility when travelling by air. 2006. 9p.

GAZETA DO POVO. Passageiros elegem Afonso Pena como o melhor aeroporto do país em 2015. 9 de março de 2016. Disponível na internet por http em:

<http://www.gazetadopovo.com.br/vida-e-cidadania/passageiros-elegem-afonsopena-como-o-melhor-aeroporto-do-pais-em-2015-2qe6rjnex48474ihyzzsbc4rn> Acesso em 02 mai. 2016

IBGE - Instituto Brasileiro de Geografia e Estatística. Censo demográfico 2010: Características gerais da população, religião e pessoas com deficiência. 2010. 211p.

INFRAERO. Anuário estatístico operacional 2015. Disponível na internet por http em: $<$ http://www.infraero.gov.br/index.php/br/estatistica-dos-aeroportos.html> Acesso em 07 mai. 2016 
PORIA, Y.; REICHEL, A.; BRANDT, Y. The flight experiences of people wih disabilities: an exploratory study. Journal of travel research 49 (2) 2010. P. 216-227

SOUZA, J. B. G. Acessibilidade em viagens de avião: o cenário regulatório e as necessidades das pessoas que demandam assistência especial. Tese. Doutorado em Engenharia de Produção. Universidade Federal de São Carlos. São Carlos, 2014 STORY, Molly Follette; MUELLER, James L.; MACE, Ronald L. The Universal Design File: designing for people of all ages and abilities. Revised Edition NC State University, The Center for Universal Design. Revised Edition. 1998. 172p. 